\title{
Clinical Test Result
}

National Cancer Institute

\section{Source}

National Cancer Institute. Clinical Test Result. NCI Thesaurus. Code C77140.

The result of a laboratory, radiologic, or other clinical test performed to determine the presence, absence, or degree of a condition. 